\title{
MAPPING THE NUMBER OF PROPERTIES OFFERED ON THE REAL ESTATE MARKET
}

\author{
Eduard Hromada ${ }^{* 1}$ \\ ${ }^{1}$ Faculty of Civil Engineering, CTU in Prague, Thákurova 7, 16629 Prague 6, Czech Republic, \\ eduard.hromada@fsv.cvut.cz, +4-202-435-3720, https://orcid.org/0000-0002-8336-8710
}

\begin{abstract}
The article deals with the description of the current situation on the real estate market in the Czech Republic during the covid-19 pandemic using several selected parameters. It analyses the structure of the real estate market in terms of the number of published offers in real estate advertising per month in the category of apartments for sale and for rent. Statistical results were obtained using EVAL software, which the author of this article has been developing since 2007 at the Faculty of Civil Engineering of the Czech Technical University in Prague. This software continuously collects, analyses and evaluates advertised offers of real estate in the Czech Republic in a monthly period.
\end{abstract}

\section{Keywords}

Real estate market, software EVAL, data mining, statistics

\section{JEL Classification}

R11 Regional Economic Activity: Growth, Development, Environmental Issues, and Changes R21 Housing Demand

R32 Other Spatial Production and Pricing Analysis

DOI: https://doi.org/10.14311/bit.2021.01.08

Editorial information: journal Business \& IT, ISSN 2570-7434, CreativeCommons license (c) (i) published by CTU in Prague, 2021, http://bit.fsv.cvut.cz/ 


\section{Introduction}

This article analyses the current situation on the housing market in the Czech Republic. EVAL software was used to map and evaluate changes in the real estate market, which continuously collects, analyses and evaluates advertised real estate offers. The collection of information from the real estate servers has been carried out regularly by an automated mechanism over a period of one month, continuously since 2007.

\section{Statistical results from the analysis of the real estate market in the Czech Republic}

\section{Apartments for sale}

Figure 1 shows the number of published offers in real estate advertising per month in the category of apartments for sale. The time interval January 2018 to June 2021 is shown. The individual curves represent individual regions in the Czech Republic. The input data include flats of all sizes, regardless of whether it is a new building or an older building.

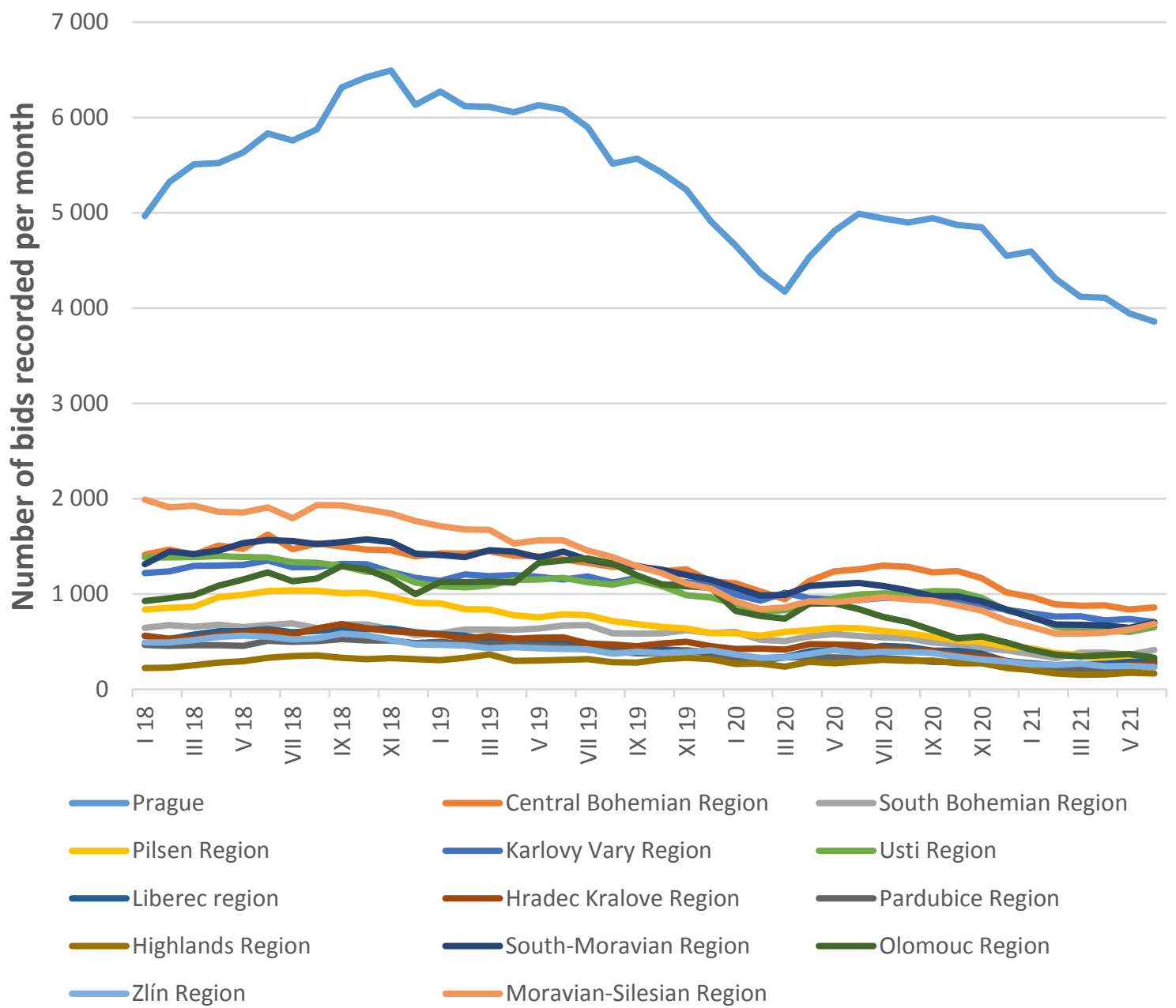

Figure 1: The number of published offers in real estate advertising per month in the category of apartments for sale, January 2018 to June 2021

Source: Software EVAL 
Figure 1 shows the time period before the onset of the covid-19 pandemic and the period of the ongoing covid-19 pandemic. The blue curve marks the Prague region. This is a specific region where unit sales prices are at a significantly higher price level. It is clear from the figure that until the onset of the pandemic, the number of apartments offered for sale is gradually decreasing. At the moment of the start of the pandemic, however, there is a turning point and the number of apartments offered for sale is growing rapidly. However, after overcoming the initial shock within a few months, the real estate market is stabilizing, and the number of apartments offered for sale continues to decline.

Currently, the situation is very extreme, when buyers do not have the opportunity to find an adequate property to buy at the right price. The real estate market is completely sold out. In the event that a smaller apartment suitable as an investment appears in the offer of real estate advertising, it is common for 30 interested parties to respond to the advertisement. Many of these investors do not even need to get a mortgage loan to buy an apartment. They have cash available. Therefore, real estate agencies use this situation in some cases and organize auctions for potential buyers. This leads to an unprecedented situation where the purchase price may be higher than the originally offered price in real estate advertising. Before the start of the pandemic, it was common for the difference between the offer price and the actual purchase price to reach 10 to $12 \%$.

In other regions of the Czech Republic, there were no such large differences in the number of properties offered as in Prague compared to the normal situation. The number of properties offered for sale in other regions of the Czech Republic is gradually declining. The problems in Prague are also caused by the fact that Prague is specific in that there is a great dependence on tourism and the work of foreign workers. After the start of the pandemic, tourism was completely paralyzed, and foreign workers left the Czech Republic massively. Many residential properties in Prague (apartments, hotels) have thus temporarily lost their use.

\section{Apartments for rent}

Figure 2 deals with the number of properties offered for rent in individual regions in the Czech Republic. The Prague region also stands out from normal behaviour. After the start of the pandemic, Airbnb apartments lost use. These flats were transferred to the long-term rental market in large numbers. The owners of these apartments thought that it was better for them to have a lower income from long-term rental than no income. In the first phase of the pandemic, landlords often concluded only short-term leases with tenants for a period of, for example 3 months, expecting a return to normalcy. However, the pandemic has been shown to continue, so these contracts have been extended.

On the other hand, there are many people interested in rental housing (especially the younger age without obligations) who wanted to try the atmosphere of living in the historical centre of Prague for a very low price. This unprecedented situation is not immediately repeated for tenants, so it is necessary to use it. These tenants took the risk that in the event of an end to the pandemic, they would have to leave the apartment in the centre of Prague.

A closer examination of the blue curve expressing the Prague region reveals that the increase in the supply of flats offered for rent has been taking place since January 2021, before the first case of covid-19 was recorded in the Czech Republic. This fact is due to the fact that problems with covid-19 in Asia began at the turn of 2020/2021 and therefore Asian tourists limited travel to the Czech Republic.

Due to the pandemic, there is a significant increase in the number of apartments offered for rent in all tourist destinations in the Czech Republic. Other regions of the Czech Republic were significantly less affected by the pandemic in terms of the rental housing market. We can observe a slight increase 
in the number of apartments offered for rent, for example in Brno, Olomouc, Český Krumlov and České Budějovice.

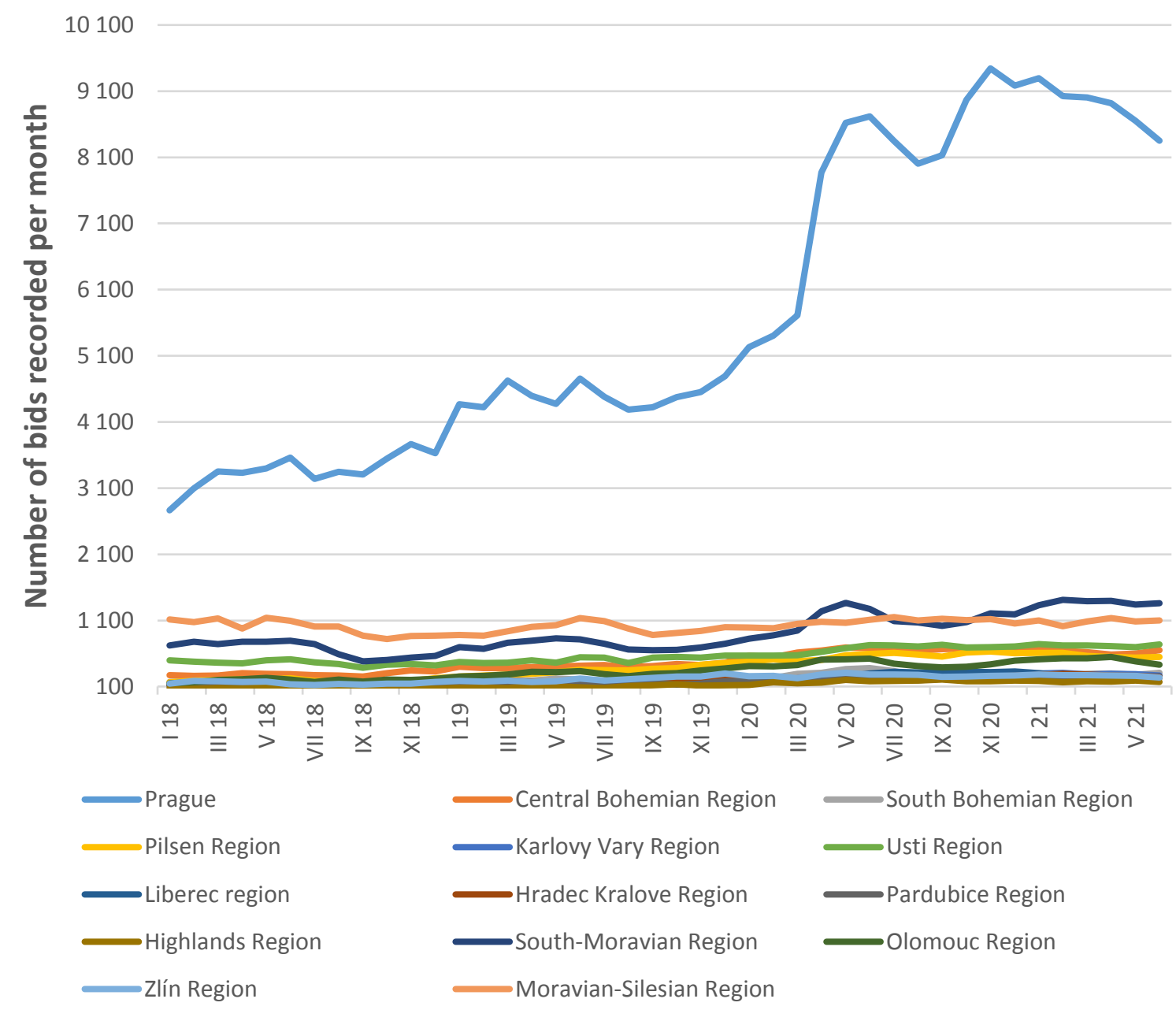

Figure 2: The number of published offers in real estate advertising per month in the category of apartments for rent, January 2018 to June 2021

Source: Software EVAL

\section{Real estate market turnover by region}

Figure 3 and Figure 4 show percentage ratio of individual regions on the real estate market turnover in the Czech Republic. Apartments for sale and apartments for rent are examined separately. It was found that in both cases the Prague region significantly dominates the real estate market. In addition, the rental market in Prague significantly exceeds the market for apartments for sale in Prague. The second and the third most important regions in terms of the volume of real estate transactions are Moravian-Silesian Region and South-Moravian Region. The high number of real estate transactions is also due to the fact that there are large cities in these two regions. The smallest volume of real estate transactions takes place in Pardubice Region and Highlands Region. 


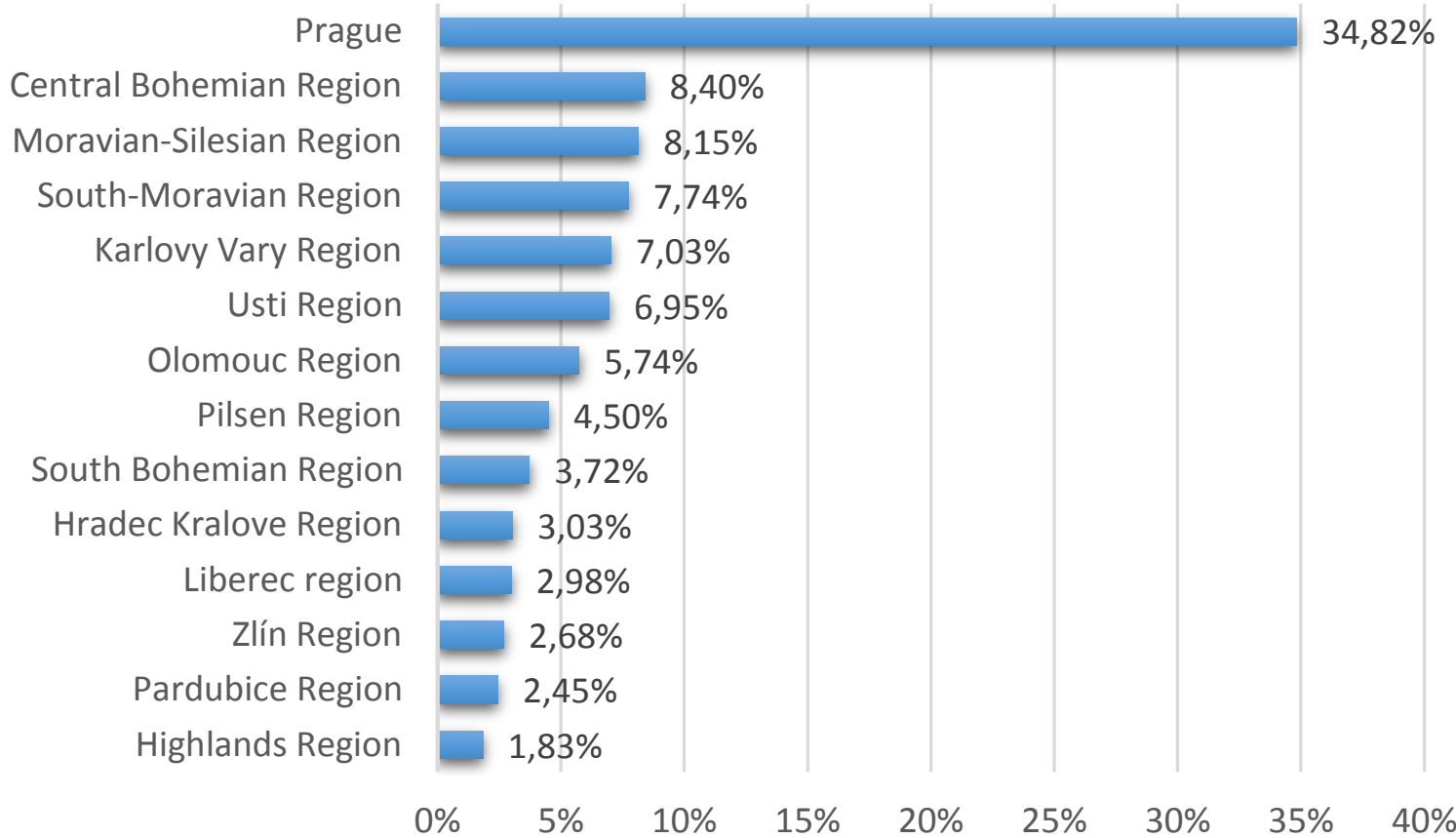

Figure 3: Percentage ratio of individual regions on the real estate market turnover in the Czech Republic in the category of apartments for sale, January 2018 to June 2021

Source: Software EVAL

Prague

Moravian-Silesian Region

South-Moravian Region

Usti Region

Central Bohemian Region

Pilsen Region

Olomouc Region

South Bohemian Region

Zlín Region

Liberec region

Karlovy Vary Region

Hradec Kralove Region

Pardubice Region

Highlands Region

\begin{tabular}{|c|c|}
\hline & $8,91 \%$ \\
\hline & $8,38 \%$ \\
\hline $5,11^{\circ}$ & $\%$ \\
\hline $4,36 \%$ & \\
\hline $3,69 \%$ & \\
\hline $3,16 \%$ & \\
\hline $2,08 \%$ & \\
\hline $1,97 \%$ & \\
\hline $1,84 \%$ & \\
\hline $1,79 \%$ & \\
\hline $1,75 \%$ & \\
\hline $1,56 \%$ & \\
\hline $1,19 \%$ & \\
\hline
\end{tabular}

$54,21 \%$

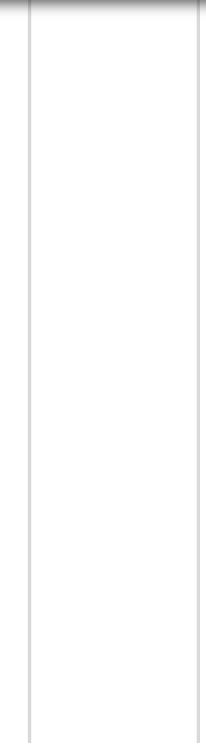

$\begin{array}{llllll}0 \% & 10 \% & 20 \% & 30 \% & 40 \% & 50 \%\end{array}$

Figure 4: Percentage ratio of individual regions on the real estate market turnover in the Czech Republic in the category of apartments for rent, January 2018 to June 2021

Source: Software EVAL 


\section{References}

[1] Hromada, E. (2016). Real estate valuation using data mining software. Paper presented at the Procedia Engineering, pp. 284-291. doi:10.1016/j.proeng.2016.11.621.

[2] Hromada, E. (2015). Mapping of real estate prices using data mining techniques. Paper presented at the Procedia Engineering, pp. 233-240. doi:10.1016/j.proeng.2015.10.083.

[3] Hromada, E. (2013). Decision-support tools and assessment methods. Paper presented at the CESB 2013 PRAGUE - Central Europe Towards Sustainable Building 2013: Sustainable Building and Refurbishment for Next Generations, pp. 669-672. 